\title{
Povos da Floresta: um estudo das nuances e das sinergias entre os Seringueiros do Acre e os Faxinalenses do Paraná, Brasil
}

\author{
Pueblos del bosque: un estudio de los matices y sinergias \\ entre los recolectores de goma de Acre y los Faxinalenses de \\ Paraná, Brasil
}

\section{Forest Peoples: a study of nuances and synergies between the 'Seringueiros' of Acre and 'Faxinalenses' of Paraná, Brazil}

\author{
Tiago Augusto Barbosa \\ tiagoaugustobarbosa@gmail.com \\ Universidade Estadual de Ponta Grossa, UEPG, Ponta Grossa, PR \\ Alexsande de Oliveira Franco \\ aofrancoufac@hotmail.com \\ Universidade Federal do Acre, UFAC, Rio Branco, AC
}

Resumo: A partir da perspectiva biogeográfica, no sentido da Geografia Física aliada a aspectos sociais, econômicos, ecológicos e culturais, empreende-se um ensaio traçando um estudo comparativo das nuances e sinergias entre os povos da floresta em dois extremos do Brasil. Para tanto selecionou-se duas comunidades tradicionais: dos seringueiros do Seringal Porongaba, na Amazônia, no estado do Acre, e os povos de sistemas Faxinais, do Faxinal Sete Saltos de Baixo, nos Campos Gerais do Paraná. Entre as nuances, destacam-se, por exemplo, o fator geográfico, as características das áreas e as atividades produtivas. Em relação às sinergias, mencionamos a gestão ecológica, sociocultural e territorial.

Palavras Chave: Resiliência, adaptabilidade, modo de vida, Biogeografia.

Resumen: La Biogeografía se presenta como uno de los campos de estudio de la Geografía Física que se relaciona con los aspectos sociales, económicos, ecológicos y culturales. A partir de esta perspectiva se emprende un ensayo con vistas a trazar un estudio comparativo de matices y sinergias entre los pueblos de los bosques en extremos de Brasil. Para ello se escogió dos comunidades tradicionales: de los colectores de goma en Seringal Porongaba en el estado de Acre, y los pueblos de los sistemas Faxinales, en Faxinal Sete Saltos de Baixo, en Campos Gerais del Paraná. Entre los matices, destacamos, por ejemplo, el factor geográfico, las características de las áreas y las actividades productivas. En cuanto a las sinergias, mencionamos la gestión ecológica, sociocultural y territorial.

Palabras clave: Resiliencia, adaptabilidad, modo de vida, Biogeografía.

Abstract: Biogeography presents itself as one of the fields of study of Physical Geography, related to social, economic, ecological and cultural aspects. From this perspective, this essay drawn up a comparative study of nuances and synergies among forest peoples in two extremes of Brazil. Two traditional communities were sampled: the 'seringueiros' of the Seringal Porongaba in the state of Acre, and the people of Faxinal Sete Saltos de Baixo, at Campos Gerais, in the state of Paraná. Among the 
nuances, we highlight, for example, the geographical factor, the characteristics of the areas and the productive activities. Regarding synergies, we mention ecological, sociocultural and territorial management.

Keywords: Resilience, Adaptability, Lifestyle, Biogeography.

\section{INTRODUÇÃO}

O Brasil é um país de dimensões continentais que abriga muitas populações minoritárias consideradas tradicionais, distribuídas em todas as regiões. A palavra 'tradicional' associada à 'população' torna a expressão bastante complexa, e não significa 'pobre' ou 'atrasada' (PIMENTEL; RIBEIRO, 2016).

A legislação brasileira, através do Decreto nº . 6.040, de 7 de fevereiro de 2007, define como povos e comunidades tradicionais:

Grupos culturalmente diferenciados e que se reconhecem como tais, que possuem formas próprias de organização social, que ocupam e usam territórios e recursos naturais como condição para sua reprodução cultural, social, religiosa, ancestral e econômica, utilizando conhecimentos, inovações e práticas gerados e transmitidos pela tradição (BRASIL, 2007, Art. $3^{\circ}$ )

As populações tradicionais englobam grupos de quilombolas, faxinalenses, seringueiros, extrativistas, quebradores de coco, ribeirinhos, caboclos, entre outros, cada um ocupando um determinado espaço geográfico. Nesse contexto constituem tema de estudo da Biogeografia, que trata dos seres vivos e sua distribuição ao longo do tempo no planeta, e da Geografia Humana, ao envolver questões socioculturais, econômicas e ecológicas.

Essa perspectiva se refere a uma ecologia vinculada à Biogeografia Humana ou Antropogeografia, na qual a preocupação na discussão está baseada na construção de identidade dos povos, aliada à articulação de conhecimento desses sujeitos. Nessa direção, Morin e Moigne (2000) apresentam a necessidade de estabelecer o pensamento complexo como alternativa à fragmentação dos saberes. Isso pode desvendar novas formas de entendimento da Biogeografia, principalmente aquela que envolve os etnosaberes dos povos tradicionais.

Este ensaio pretende abordar uma comparação de nuances e sinergias entre dois povos da floresta no território brasileiro, os seringueiros da floresta amazônica que vivem na Reserva Extrativista Chico Mendes, no Seringal Porongaba, e os agricultores faxinalenses do Faxinal Sete Saltos de Baixo, da floresta com araucária dos Campos Gerais do Paraná, no sul do Brasil (Fig. 1). Busca-se uma cadência de articulações entre campos do saber com a finalidade de conceber uma discussão contributiva às ciências, especialmente nos campos da Geografia, Antropologia e Sociologia. Para tanto a construção da discussão apoia-se em uma abordagem biogeográfica sistêmica, além de experiências empíricas e práticas nas respectivas áreas no norte e sul do país. 
Para além da perspectiva puramente naturalista, muito difundida na Biogeografia, se mostra a possibilidade de encadeamento sistêmico, através de da variável humana, trazida à luz do debate, como forma de organizar novas fronteiras de saberes, interligando epistemologicamente os sujeitos ('senso comum').

Figura 1: Localização das comunidades estudadas.

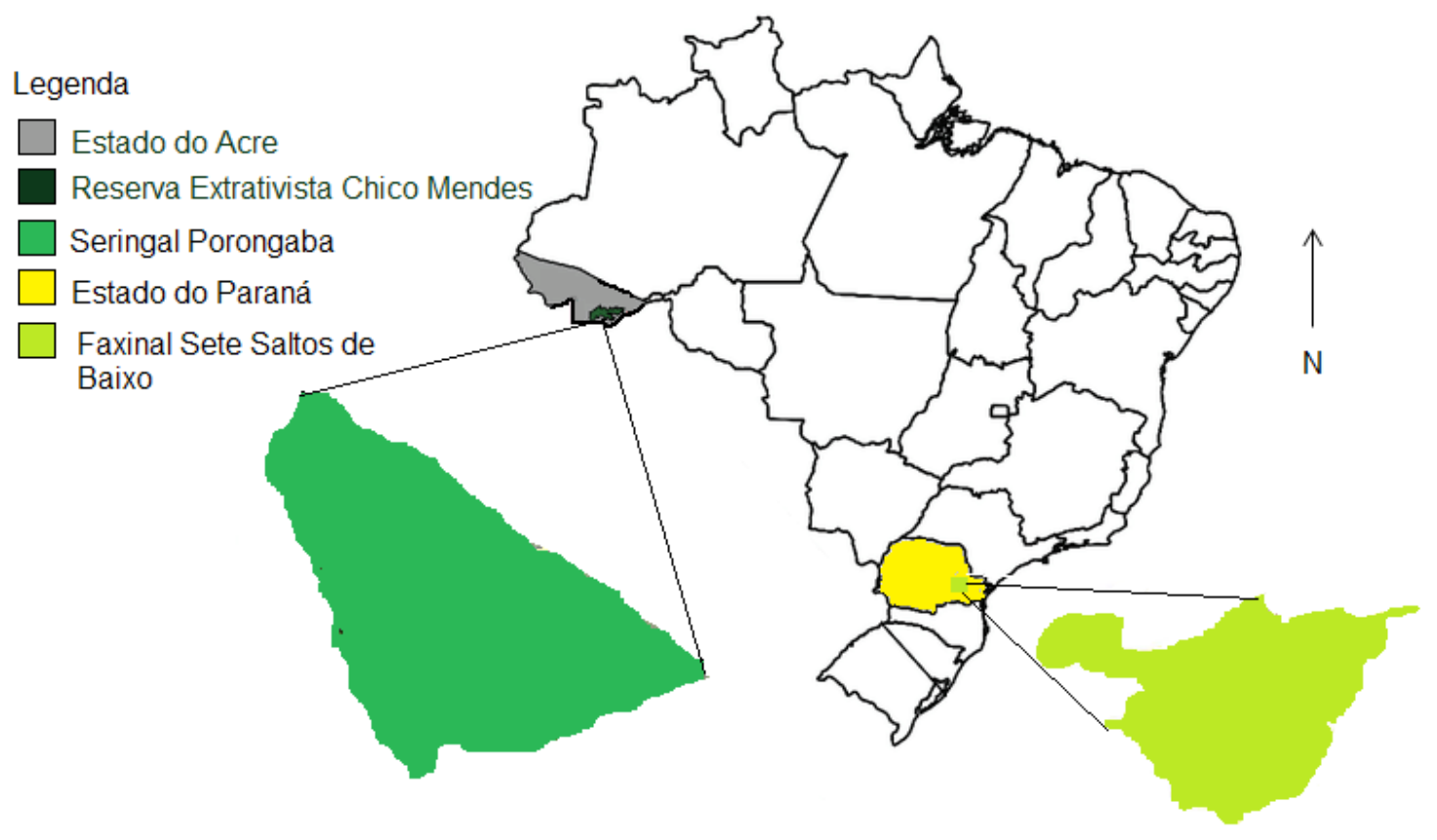

Fonte: os autores

Corroborando com as perspectivas conceituais integradoras, inserem-se na discussão as contribuições de sistemas presentes nos trabalhos de Fritjof Capra em sua Visão Sistêmica da Vida (CAPRA; LUISI, 2014), aliado às nuances e possibilidades apontadas pelos Geossistemas, como pode ser encontrado em Christopherson (2012). Nesse sentido, a constituição dos encadeamentos sistêmicos se dá através da percepção de um contínuo biogeográfico alicerçado na distribuição dos grupos, nas formas de uso, ocupação, nuances e sinergia com os ambientes naturais, externados pelo diagnóstico comparativo e interpretativo de duas realidades geográficas Norte e Sul, seringueiros e faxinalenses.

\section{A BIOGEOGRAFIA E SUA RELAÇÃO HUMANA - COMPREENDENDO A ABORDAGEM}

A Biogeografia, por essência, se apresenta como responsável por conceber investigações e apreensões acerca da distribuição dos seres vivos no planeta, ao mesmo tempo em que busca compreender seus mecanismos de funcionamento e reprodução. Pode-se afirmar que a perspectiva histórica da Biogeografia apresenta um conjunto de lições do passado que podem e devem ser aplicadas no presente e em cenários futuros, na forma de 
conhecimentos vernaculares e científicos passados entre gerações. No oposto do espectro apresenta-se a perspectiva ecológica a partir de aspectos físicos e naturais que estabelecem ativos de ordem para a distribuição dos seres vivos, como elementos de especiação, relações harmônicas e desarmônicas, barreiras de limite de distribuição, etc.

A união dos aspectos permitiria perceber uma Biogeografia Humana nos termos tradicionais dos estudos em Biogeografia? Entende-se que sim, e este ensaio busca diálogos entre um campo outrora restrito à descrição ecológica, agora com outra roupagem, não necessariamente nova, mas com grandes potencialidades de debate e ampliação do bojo dos saberes científicos e tradicionais.

Em termos de entendimento de uma Biogeografia Humana, há que se atentar para uma condição essencial, a percepção da sustentação dos grupos humanos no ambiente, em variadas escalas. Para Figueiró (2015), pensar a natureza como pura e simplesmente depósito de recursos naturais indica um caminho de capitalização extrema, uma financeirização do que, necessariamente, é muito mais complexo do que produtos vendáveis, por tratar-se de subsistência humana, orgânica, social, econômica e cultural. $\mathrm{O}$ autor aponta ainda outra alternativa viável, uma terceira via talvez - que não a financeirização nem o extremo da proteção integral, mas sim uma percepção das práticas de natureza com a sociedade, incorporando inúmeros valores tanto à natureza quanto à sociedade humana.

Ao iniciar o primeiro capítulo da obra A Economia da Natureza, Robert Ricklefs (2009) convida à reflexão, destacando um desafio lançado por William Cronon na obra Uncommon Ground (1995 p. 171-185), irradiada pela organização de duas percepções acerca da natureza e das relações humanas com esta. A primeira e refere a que a natureza tende ao equilíbrio auto restaurador se não for perturbada. Por outro lado, a ausência de seres humanos no mundo empreenderia um estado de natureza prístina. Independentemente da validação científica destas percepções (as quais apresentam defensores e críticos), a provocação do autor pressupõe que a partir dos elementos culturais, desenvolvidos em determinado grupo ou sociedade, moldamos nossa visão em relação à natureza.

Assim, a relação com o ambiente depende dos valores e crenças, de como os seres humanos são percebidos como parte integrante do mundo natural. A visão integrada é fundamental para o equilíbrio dos sistemas ecológicos, assim a abordagem sistêmica e biogeográfica pode, sem dúvida, ser empregada no contexto da Geografia Humana com um perceptível potencial de aplicabilidade. "A pesquisa biogeográfica deve preocupar-se sempre com o enfoque da 'distribuição espacial' dos seres vivos associado ao caráter 'Antropocêntrico', isto é, o Homem (a Sociedade) não pode ser excluído do complexo biogeográfico" (CAMARGO; TROPPMAIR, 2002, p. 135).

Ainda de acordo com esses autores:

(...) um trabalho biogeográfico do ponto de vista do 'geógrafo', tem necessidade de explicar a distribuição dos seres vivos (fauna e flora) no espaço, e correlacioná-las sempre com os demais aspectos ambientais (fatores abióticos) e o próprio Homem (fatores culturais), apresentando, assim, uma visão muito mais ampla e complexa (CAMARGO; TROPPMAIR, 2002, p. 135). 
A perspectiva deste ensaio é também dialogar a partir desta tradicional dicotomia, na tentativa de extrapolar suas fronteiras promovendo a intersecção de saberes e campos científicos. Para árdua tarefa, empreende-se uma ideia introdutória proveniente das ciências biológicas, acerca da vida sistêmica.

De acordo com Maturana e Varela (1995) a vida é caracterizada por uma série de elementos funcionando em sinergia, dentre os quais se destaca a característica essencial de automanutenção. A esta característica chamaram de autopoiese, em referência à auto-organização e à ação cíclica de regulação, ou simplesmente ação. Percebendo a sugestão de auto sustentação proposta é possível pensar em uma aproximação com o ideário motivador deste ensaio, que são, em essência, grupos humanos, tradicionais que apresentam determinado grau de autopoiese, alicerçados pelos perfis de subsistência, resiliência e adaptabilidade ao ambiente e aos sistemas sociais, ecológicos, econômicos e culturais.

Bertalanfy (1975) e Capra e Luisi (2014) trazem contribuições significativas à perspectiva sistêmica, onde evidenciam a conectividade [inter-relação] dos seres vivos com seus respectivos ambientes, as dinâmicas emergentes, a auto-organização e ainda a retroalimentação do sistema com entradas (inputs) - por exemplo, políticas públicas implantadas - e saídas (outputs) - resultado das politicas públicas implantadas.

Dessa forma, a constituição de uma base científica apresenta uma égide bastante significativa, onde os sistemas assumem caráter de guia ou base para o desenvolvimento de pesquisas com essa tônica, interconectividade latente com articulações sinérgicas e áreas de fricção.

\section{POPULAÇÕES TRADICIONAIS NA AMAZÔNIA - OS SERINGUEIROS}

A Amazônia apresenta características socioculturais e ecológicas particulares, seja pela biodiversidade, seja pela diversidade de grupos étnicos denominados tradicionais, quais sejam seringueiros, caboclos, ribeirinhos, entre outros. Embora cada grupo possua uma identidade particular, utilizam os mesmos recursos (da floresta).

Os seringueiros ocupam, em sua grande maioria, unidades de conservação, em especial Reservas Extrativistas (RESEX) e apresentam características culturais conforme o território em que vivem.

Para Allegretti (2008, p. 57)

A política de criação de áreas protegidas para o uso sustentável de populações tradicionais teve êxito politicamente porque criou um mecanismo institucional de resolução de conflitos em torno da terra e da floresta; socialmente, porque assegurou meios de vida para as gerações atuais e futuras; culturalmente, porque respeitou formas tradicionais de uso dos recursos naturais; e ambientalmente, porque impediu o avanço dos desmatamentos. 
Essas áreas tiveram papel relevante na construção do modo de vida ${ }^{1}$ das comunidades tradicionais, sobretudo, dos seringueiros. Para os seringueiros a borracha sempre foi uma atividade importante, desde a ocupação da região e motivo inicial para a migração, e a estrutura dos seringais sempre esteve ligada ao extrativismo.

De acordo com Diegues (1996) o isolamento relativo dessas populações leva ao desenvolvimento de modos de vida particulares que envolvem grande dependência dos ciclos naturais, conhecimento profundo dos ciclos biológicos e dos recursos naturais. Esses sujeitos tem uma historia de lutas contra a fome e a devastação da floresta, onde os 'empates $^{\prime 2}$ foram o símbolo da resistência seringueira. Da luta e reivindicações dos seringueiros e de outros grupos tradicionais, durante a década de 1980, as politicas públicas convergiram à criação de pelo menos uma categoria de áreas protegidas, a RESEX, denominada de "reforma agrária dos seringueiros", oriunda da luta pela identidade dos seringueiros, explorados secularmente pelos patrões da borracha nativa na Amazônia (CNS, 1992).

Esse grupo tradicional que historicamente sobreviveu da extração do látex organizou toda a estrutura territorial, social e econômica do território ligado a um modo de vida que se baseia na utilização dos recursos naturais extraídos da floresta e da agricultura familiar de subsistência. A cultura do seringueiro é caracterizada pelo processo de integração com a natureza, na compreensão das interações existentes entre os ciclos naturais e o uso dos recursos naturais e artificiais construídos.

O seringal é estruturado em 'colocações'3 (Fig. 2). Cada colocação possui ao menos 200 hectares, o que corresponde a uma estrada (percurso) de 'seringa' ${ }^{4}$ - no entanto encontram-se colocações maiores ou menores em função da subdivisão familiar. As estradas de seringa delimitam colocações e seringais. Nos seringais há uma dinâmica gestão territorial, com áreas destinadas ao extrativismo, à criação de animais e à produção agrícola.

Com relação ao uso da terra nos seringais tem-se:

1. varadouros, que são os caminhos e estradas pelos quais o seringueiro se desloca dentro da colocação para atingir as estradas de seringa e outras partes do seringal.

2. roçados plantados onde desenvolvem cultivos anuais e perenes (milho, arroz, banana, entre outros), sobretudo para subsistência. Produzem durante dois ou três anos até abandono do roçado e criação de outro através do corte e queima de novas parcelas da floresta.

3. criadouro de animais domésticos como gado, galinhas, suínos, entre outros, para alimentação do grupo e potencial venda, se necessário, além da residência do morador. O plano de manejo das RESEX estabelece que entre 5\% a 10\% do território do seringal se destine à agropecuária e o restante para atividades extrativistas (BRASIL, 2006). A pecuária, dentro do regulamentado da RESEX, é uma atividade fundamental para manter a renda familiar.

\footnotetext{
1 Considera o descrito por Franco e Löwen Sahr (2019), para quem 'modo de vida' seria o conjunto de elementos estreitamente vinculado à cultura, ao território, ao coletivo, a subjetividade, a história de vida e as técnicas empreendidas .

2 Luta dos seringueiros onde os mesmos davam as mãos para empatar/ inibir o desmatamento das florestas.

3 Local onde é produzida a borracha no seringal.

4 Percurso para coleta de látex das seringueiras, cuja dimensão varia dependendo do local.
} 
4. extrativismo de recursos da fauna e flora. Podem ocorrer a caça de animais silvestre para consumo (cutia, paca, anta, macaco, etc.) e a pesca para aqueles que vivem próximos aos rios e igarapés, coleta de castanha, corte da árvore seringueira ${ }^{5}$ para extrair o látex e produzir borracha. Essa atividade é realizada atualmente com menor intensidade devido à queda do preço da borracha no mercado.

Figura 2: Representação das colocações no território de um seringal. 1 - Varadouro; 2 - Roçados; 3 - Criadouro; 4 - Extrativismo.

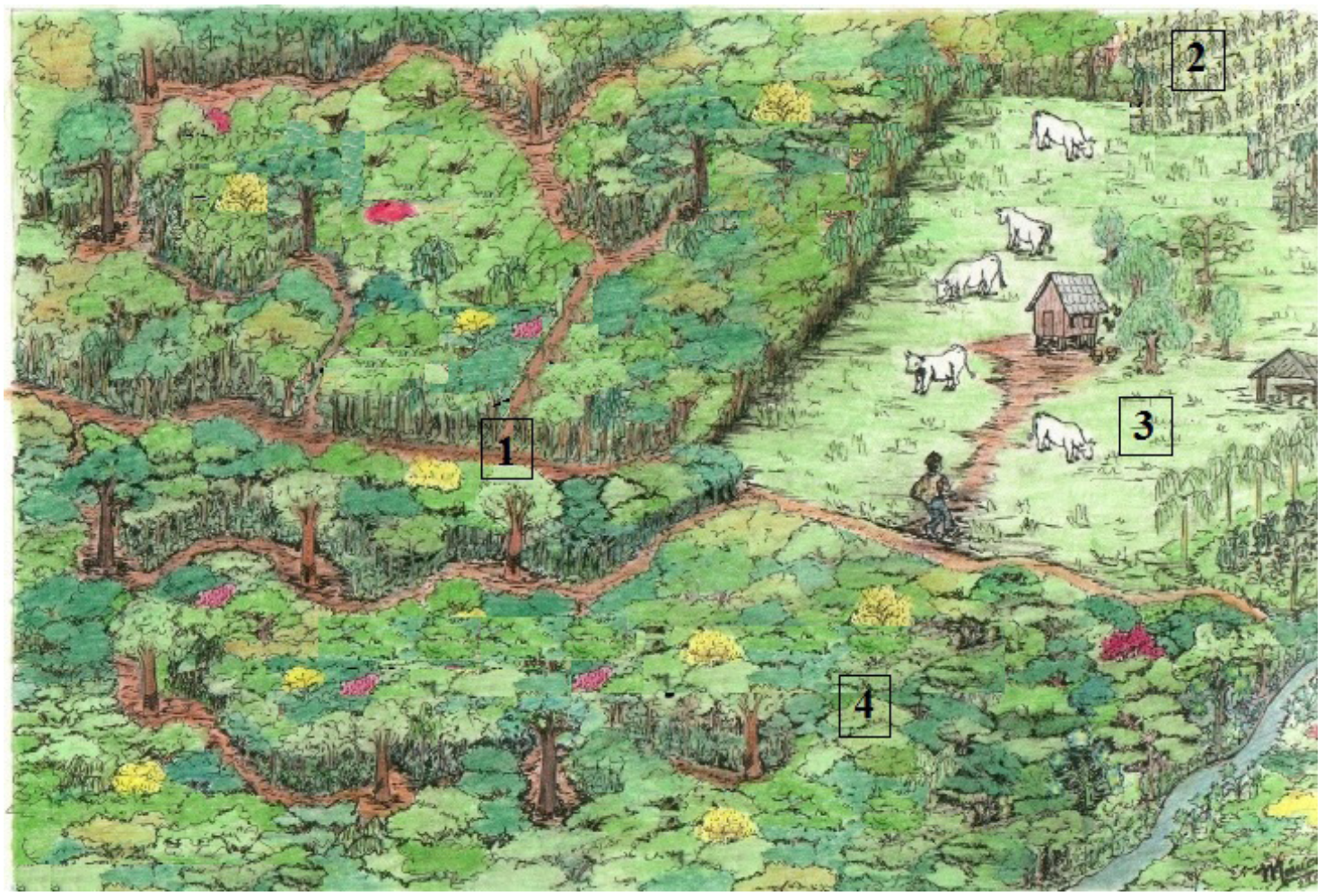

Fonte: Alechandre (2007)

Como a extração do látex foi por muito tempo a principal fonte de renda dos que viviam nos seringais, Gomes (2018) menciona que a economia da borracha favoreceu a preservação da espécie, ao absorver por um bom tempo toda a mão de obra disponível na região. O seringueiro apresenta um conhecimento da natureza e de experiências positivas e negativas ao longo das décadas que é transferido para seus descendentes e se reflete na elaboração de estratégias de uso e de manejo dos recursos naturais, sempre inclinada aos aspectos ecológicos. Assim, a cultura tradicional do seringueiro está baseada no que se costuma chamar de "conservadorismo cultural" que implica em um comportamento mais prudente em termos ambientais (ACRE, 2000).

No entanto, o número de seringueiros que desenvolve essa atividade vem diminuindo nas últimas décadas devido ao baixo valor de mercado da borracha. Consequentemente a cultura seringueira passou, e ainda passa, por um processo de transformação e diversificação

5 Sangria da árvore para extrair o látex. 
econômica fundamental para manter sua sobrevivência na floresta e, nesse sentido, o modo de vida seringueiro tradicional como desenvolvido até meados do século $X X$ não existe mais, apenas como resquícios de produção, e principalmente como ideologia social.

Para Silva (2005), nesse contexto de produção socioespacial, a territorialização de forças econômicas e o forjamento de forças sociais na floresta levam ao surgimento de territorialidades diversas em territórios diversos. Os seringueiros tiveram que encontrar outras fontes de renda, entre as quais ampliar a coleta de sementes e frutos (castanha, bacaba, açaí, buriti, entre outros) durante um determinado período do ano para compor a renda. Também incluir nos roçados de subsistência espécies frutíferas e madeireiras - além da mandioca, arroz e feijão, também há bananeira, cupuaçu, entre outros.

Como grande parte dos seringueiros do Acre se encontra em RESEX, eles estão atrelados ao plano de manejo que limita uma série de atividades como a criação de gado em larga escala, caça e pesca predatória, agricultura intensiva. Mas talvez o principal obstáculo seja a infraestrutura precária com relação aos ramais, armazenamento, transporte e insumos. O poder público Municipal, Estadual e Federal desenvolve diversos programas que incentivam a produção sustentável, como a Política de Garantia de Preço Mínimo (PGPM) para produtos da sóciobiodiversidade desenvolvido pela Companhia de Abastecimento (CONAB) e o Programa de abertura de Ramais desenvolvido por municípios e estado.

Em uma perspectiva sistêmica a cultura seringueira desenvolve a autopoiese ambiental, com retroalimentação sistêmica alicerçada nos perfis de seus moradores, baseada na adaptabilidade ao ambiente e aos sistemas sociais, econômicos, ecológicos e culturais. Dessa forma observa-se a conectividade e interdependência dos elementos do seringal para o equilíbrio ecológico local. As atividades desenvolvidas pelos seringueiros podem interferir diretamente no sistema de diferentes formas, em geral positiva, pois em geral são baseadas na exploração racional dos recursos naturais (Fig. 4). O impacto ambiental é baixo e, dessa forma, autossustentável.

Figura 4: Organização Sistêmica Tradicional do Seringal - Seringueiros.

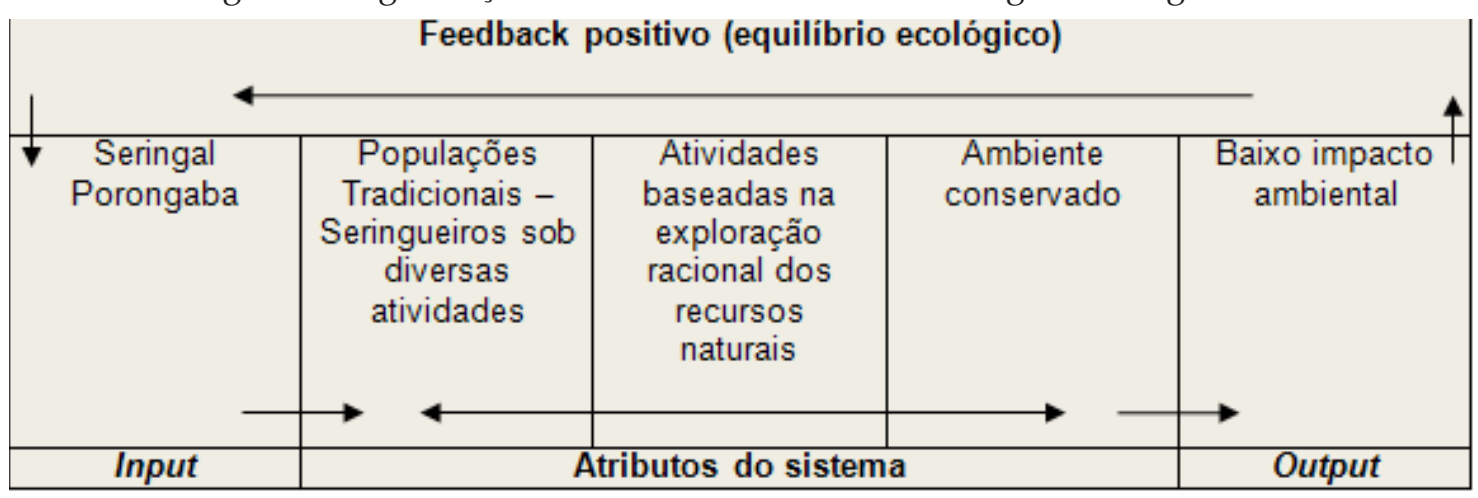

Fonte: os autores.

Por outro lado há a possibilidade de feedback negativo quando a entrada no sistema visa apenas o lucro e a exploração da natureza (Fig. 5). Um fator negativo que traz consequências diretas a cultura seringueira são as atividades impactantes de desmatamento no 
entorno e mesmo interior das RESEX, que dificulta o modo de vida dos moradores locais em detrimento de uma visão capitalista de exploração da natureza voraz de sujeição econômica. Observa-se também que o sistema agropecuário em seringais na RESEX Chico Mendes se distancia da organização tradicional, causando desequilíbrio, insalubridade e entropia.

Figura 5: Organização Sistêmica Não Tradicional do Seringal - populações não tradicionais.

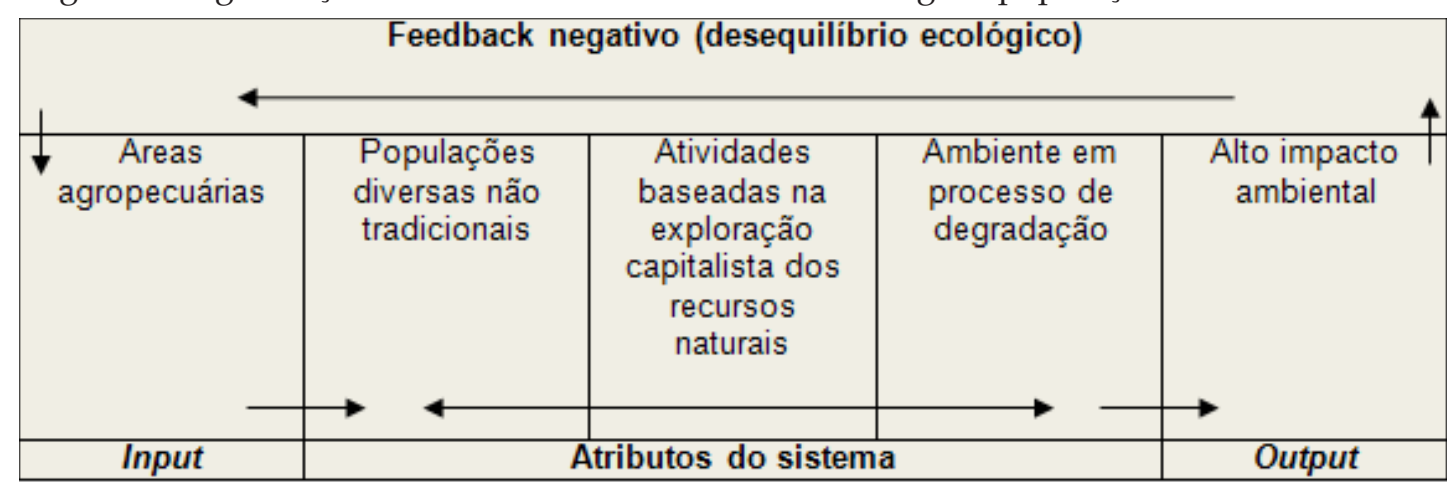

Fonte: os autores.

A cultura seringueira vive vinculada diretamente na/da floresta, dessa forma a luta desses povos combatidos continua ainda hoje, em plena segunda década do século XXI. A cultura permanece, com uma identidade forte e presente, vinculada à luta em defesa da floresta e de seu respectivo modo de vida que busca o equilíbrio com o meio e com a organização no território.

\section{POPULAÇÕES TRADICIONAIS NA FLORESTA COM ARAUCÁRIA - OS FAXINALENSES}

As comunidades em faxinais caracterizam-se por uma estrutura social e ordenação territorial singular. De acordo com Chang (1988), o Sistema Faxinal é uma forma de organização camponesa característica da região centro-sul do Paraná, na formação vegetal típica representada principalmente pela mata com araucária. A formação desse Sistema, segundo a autora, está associada a variados condicionantes de ordem físico-naturais da região, além de elementos econômicos, políticos e sociais.

De acordo com Schörner e Campigoto (2011, p. 58), os sistemas de faxinais são:

Um modo de utilização das terras em comum, existente na região Sul do Brasil, para a criação de animais e que se tem classificado como manifestação cultural pertencente à categoria dos povos tradicionais brasileiros: forma própria de uso e posse da terra, o aproveitamento ecológico dos recursos naturais - pinhão, guabirobas, araçás, pitangas, jabuticabas - o cultivo da vida comunitária e a preservação de memória comum.

Em termos de dimensão natural, o Sistema Faxinal é um mecanismo de conservação da biodiversidade (CARVALHO; FLORIANI, 2017), sendo os criadouros comunitários considerados atualmente dos últimos remanescentes expressivos de Floresta Ombrófila Mista na região dos Campos Gerais. Contam com a presença de várias espécies de grande valor 
econômico agregado, como imbuia, canela, cedro, erva-mate e a própria araucária, "merecendo o status de unidades de conservação estaduais" (FLORIANI; CARVALHO; FLORIANI, 2010, p. 2). Esta floresta, pertencente ao bioma Mata Atlântica, sofreu com a exploração predatória da Araucária (Araucaria angustifolia Bert. O.Kuntze) e, reduzida atualmente a menos de 2\% de sua área original, encontra-se fortemente ameaçada (MORO et al., 2018).

As comunidades de faxinais estão, portanto, diretamente relacionadas ao meio natural e ao coletivo, pois os faxinalenses dependem do ambiente, em sua forma de produção e reprodução, para subsistir. Esse sistema tem contribuído para a permanência da vegetação nativa e a presença de faxinais no território paranaense colaborou significativamente para a conservação de parte das florestas características do Sul do Paraná (LÖWEN SAHR, 2005).

O Sistema Faxinal compõe a vasta diversidade sociocultural brasileira, a qual é acompanhada de diferentes formas de organização e de uso da terra de populações tradicionais (LÖWEN SAHR, 2007). Essa dimensão prioriza a noção de território enquanto produto da apropriação ou valoração simbólica, nesse caso a valorização do faxinalense em relação ao seu espaço de vida. No Sistema Faxinal, a identidade dos moradores é marcadamente determinada por dois elementos principais: o meio natural e o modo de organização social, a partir destes dois elementos derivam outros, levando a formação da identidade do Faxinal. Os laços de identidade são criados e recriados cotidianamente, assim como a bracatinga que sempre nasce de novo: queima e rebrota. As dinâmicas relacionais cotidianas constituem afirmações da identidade do território faxinalense.

Tradicionalmente o Sistema Faxinal se assemelha a outras formas de organização rural que mantém um eixo familiar de produção, entretanto sua singularidade está no caráter coletivo do uso da terra para a produção animal e estruturação social, ainda que a propriedade da terra continue sendo particular. Suas terras estão divididas em dois espaços principais: o criadouro comunitário e as 'terras de plantar' (Fig. 6).

Figura 6. Territorialização esquemática de um Faxinal. 1 - Criadouro; 2- Terras de Plantar; 3- Vegetação; 4 - Cercas e Valos.

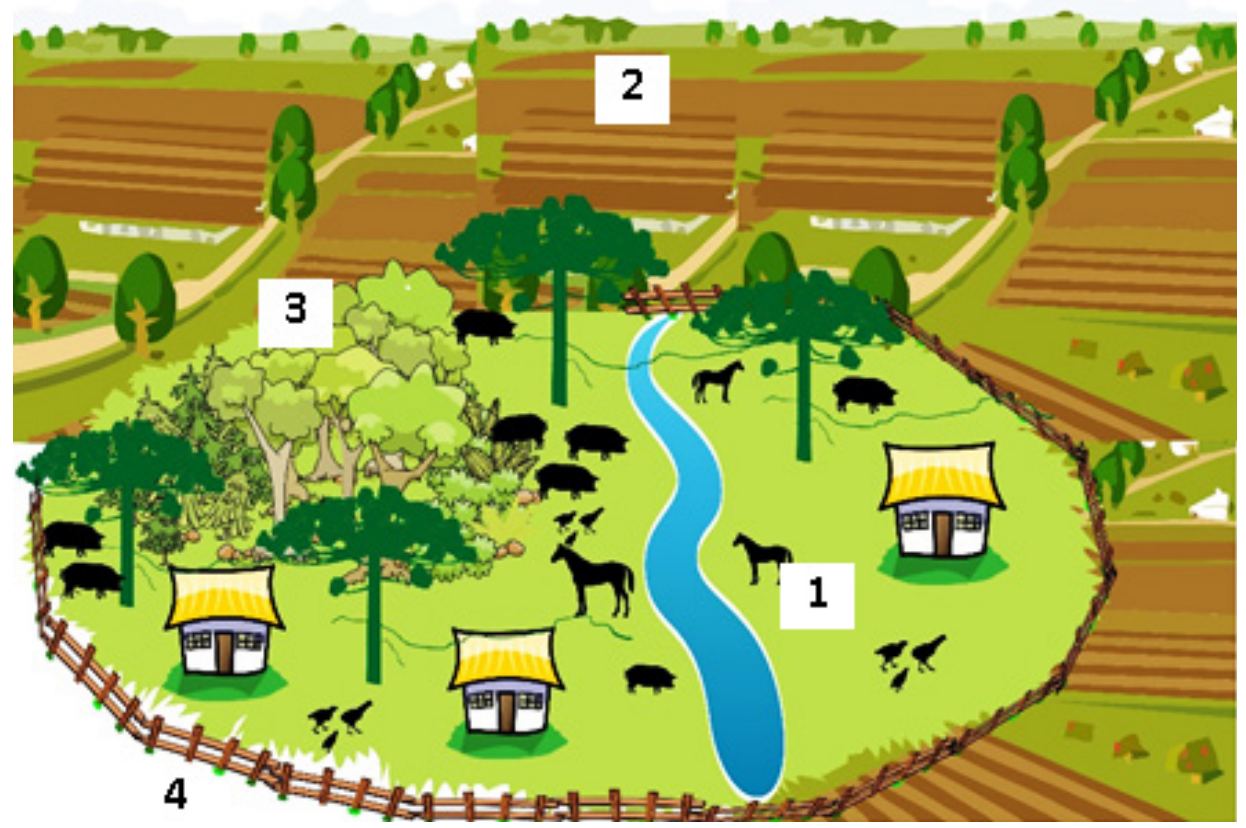

Fonte: os autores. 
As atividades produtivas do Sistema Faxinal se amparam principalmente na atividade silvo pastoril, que se materializa no criadouro comunitário. Neste residem os membros da comunidade e é onde também se criam os animais, tanto gado miúdo (suínos e caprinos) quanto gado graúdo (ovinos equinos), de forma coletiva e solta na floresta. Também ocorre o extrativismo sustentável de erva-mate, arvoreta do sub-bosque dos pinhais, atividade que agrega renda e é bastante marcante do Sistema Faxinal. Embora o uso do criadouro comunitário seja coletivo, a exploração da erva-mate e a produção animal são caracteristicamente privadas, ainda assim aqueles que não têm propriedade sobre a terra podem morar, criar e trabalhar no criadouro comunitário.

As 'terras de plantar', cercadas e privadas, em geral são circunvizinhas ao criadouro comunitário e destinam-se basicamente a policultura de subsistência, sobretudo para o cultivo de milho e feijão.

Diante de uma estrutura organizacional ímpar, se pode notar a complexidade sistêmica nos Faxinais, que apresentam prospectivas formas de ação, desde sua dimensão social e cultural até seu modo tradicional de subsistência, mas também com indicações de elementos contemporâneos como a prática da silvicultura, da fumicultura, além do Sistema Agroflorestal (SAF). Tais considerações engendram uma percepção que pode ser apontada como pós-moderna, onde convivem elementos tradicionais com propriedades contemporâneas, sobretudo vinculadas ao modo de vida e produção.

Em termos sistêmicos, a percepção apurada se dá pela iniciativa comunitária de articulação entre modo de vida social, subsistência orgânica e econômica e, até certo ponto, sustentabilidade ambiental - se comparada a outros modos de organização social camponesa (Fig. 7).

Figura 7: Organização Sistêmica Tradicional do Faxinal - Faxinalenses.

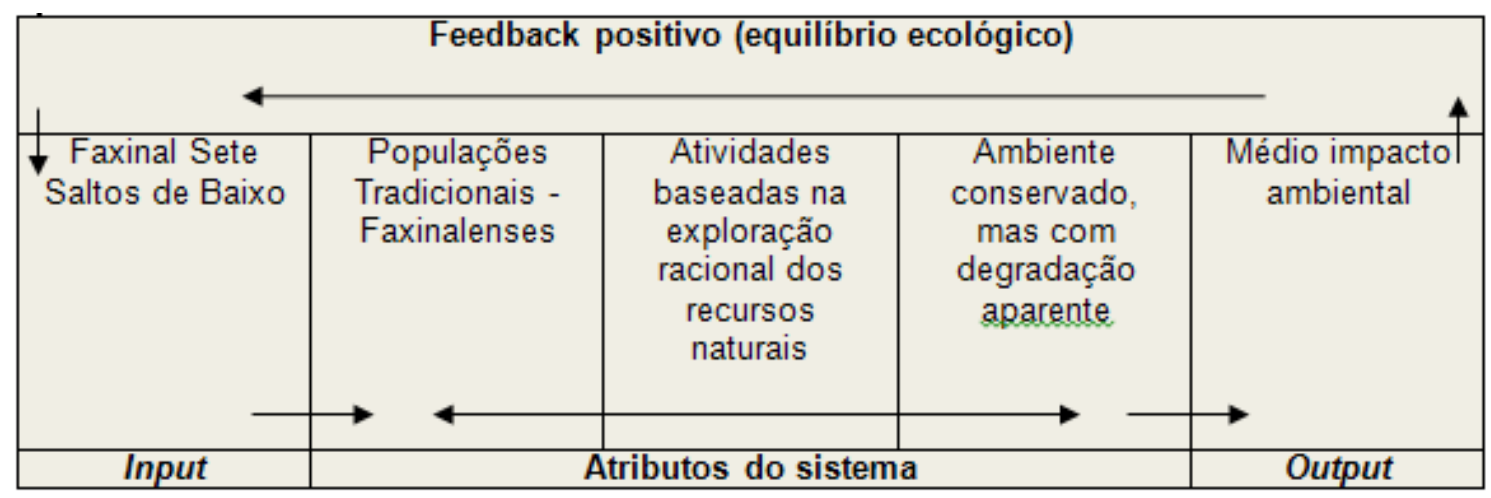

Fonte: os autores.

Ao mesmo tempo em que a produção da sobrevivência se dá por mecanismos tradicionais de cultivo da terra, por outro lado algo de moderno em termos de conservação e manutenção da geobidiversidade se apresenta vivamente aos olhos de quem se debruça sobre a temática dos Faxinais. Há, notoriamente, possibilidade de se fazer dos Faxinais um molde capitalista puramente financeiro e degradante. Como menciona Langaro (2018), Estas formas de organização, baseada na preservação ambiental e organização social coletiva, 
contrastam com as propriedades rurais mecanizadas apresentando-se como um sistema distinto da lógica capitalista (Fig. 8), caracterizada pelo desequilíbrio, insalubridade e entropia.

Figura 8: Organização Sistêmica Não Tradicional do Faxinal - populações não tradicionais.

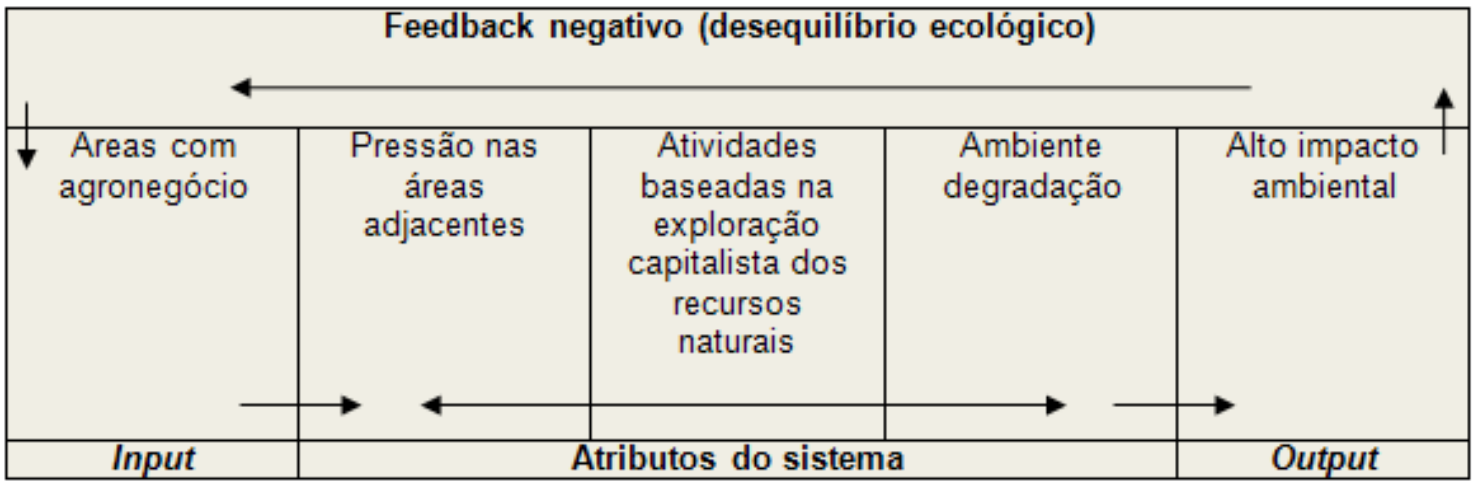

Fonte: os autores.

Dessa forma, Langaro (2018) menciona que as modificações na economia e na cultura dos faxinalenses, alteram vários aspectos da antiga forma de vida local. Observa-se que

[...] as comunidades faxinalenses veem-se constantemente em uma situação conflituosa. De um lado, buscam manter suas características tradicionais, num processo de integração sistêmica, e de outro lado, para continuar existindo vêem-se obrigadas a se abrir a dinâmicas "modernas", num processo de integração social (LOWEN SAHR, 2008, p. 216)

Conforme Grzebieluka e Löwen Sahr (2009),

Desde a sua gênese, as comunidades de Faxinal vêm mostrando uma capacidade ímpar de adaptação à dinâmica econômica das regiões onde estão inseridas, entretanto, se assiste também a um processo de desagregação deste modo de viver, o qual vem perdendo seus laços históricos, sociais e culturais do passado (GRZEBIELUKA; LÖWEN SAHR, 2009, p. 35 e 36).

Porém, de acordo com Correia e Gomes (2015), os povos de faxinais se recriam a partir de um conjunto de processos transformadores do sistema e isto não necessariamente pode ser tomado como extinção do faxinal, mas sim como novas formas de organização, novas territorialidades.

\section{DIFERENÇAS E SINERGIAS DOS POVOS DO SERINGAL E DO FAXINAL NA PERSPECTIVA BIOGEOGRÁFICA HUMANA}

Nesta abordagem sistêmica com enfoque homem, natureza e espaço geográfico, analisam-se as diferenças e sinergias entre estas duas populações tradicionais, os Seringueiros da Amazônia e os Faxinalenses no Paraná. 
Os povos da floresta aqui estudados possuem uma tecnologia ancestral centenária passada de geração a geração, com crescentes acréscimos tecnológicos contemporâneos. Nesse bojo encontram-se relações ecológicas, socioculturais e a gestão do território.

Notoriamente as nuances se destacam pelo fator geográfico, características das respectivas áreas, politicas públicas, atividades produtivas e demografia. Tais elementos diferenciadores engendram, por sua vez, as diferentes formas de compreender a área. Poder-se-ia enumerar várias outras, extensamente, contudo, para termos uma percepção mais acurada da realidade, os temas aqui demonstrados são suficientemente esclarecedores daquilo que se objetiva nesta seção do ensaio proposto.

Se de um lado as diferenças são apresentadas, somam-se também as relações sinérgicas e aproximativas que podem contribuir a uma interpretação complexa e sistêmica da realidade dos povos da floresta do norte e do sul do Brasil. Nesse sentido, são apresentados a seguir tópicos divergentes e sinérgicos que dão conotação à articulação complexa e sistêmica a que se destina esse ensaio (Quadro 1). Tem-se a concepção de associação ou articulações de situações factuais e vivenciadas em relação ao modo de vida e reprodução dos povos da floresta estudados neste ensaio.

Quadro 1: Nuances e sinergias entre os seringueiros (seringais) e faxinalenses (faxinais).

\begin{tabular}{|c|c|}
\hline \multicolumn{2}{|r|}{ Nuances } \\
\hline Espaço Geográfico & $\begin{array}{l}\text { Localização da área - Sob a égide do espaço geográfico, ficam evidentes as diferenciações, } \\
\text { sobretudo, ao se pensar na localização entre biomas - Amazônia e Mata Atlântica - além } \\
\text { de articulações recorrentes a estes compartimentos, como ativos naturais disponíveis e suas } \\
\text { consequentes transformações em recursos naturais. }\end{array}$ \\
\hline \multirow[t]{2}{*}{$\begin{array}{l}\text { Características } \\
\text { espacial e legal }\end{array}$} & $\begin{array}{c}\text { Perfil espacial das áreas - Faxinais apresentam uma área reduzida. No Faxinal Sete Saltos de } \\
\text { Baixo, de acordo com Ferreira (2009), Moro e Lima (2012) e Staniski, Floriani e Strachulski (2014), } \\
\text { há cerca de } 60 \text { famílias vivendo em } 992 \text { hectares, resignando-se às áreas comumente de fundos } \\
\text { de vale para estabelecimento do criadouro comunitário e áreas mais altas para organização das } \\
\text { terras de plantar. De outro lado, o Seringal Porongaba dispõe de aproximadamente } 9.370 \text { hectares } \\
\text { e cerca de } 30 \text { famílias, de acordo com Mascarenhas, Brown e Silva (2018). Os seringueiros se valem } \\
\text { de uma área maior, visto que a atividade motriz é o agroextrativismo. }\end{array}$ \\
\hline & $\begin{array}{c}\text { Aspecto legal - Os seringueiros utilizam a terra da União em usufruto; os faxinalenses tem a posse } \\
\text { da terra, tendo cada proprietário sua posse e sua escritura. Ambos são reconhecidos oficialmente e } \\
\text { enquadrados na Política de Populações Tradicionais. }\end{array}$ \\
\hline Politicas públicas & Federais para os seringais da Amazônia e estaduais para os faxinalenses do Paraná. \\
\hline Economia & $\begin{array}{l}\text { Atividades produtivas - Variável entre os faxinais; em Sete Saltos de Baixo a estrutura é quase } \\
\text { que integralmente voltada a agricultura de subsistência, bem como a criação de animais, com } \\
\text { pouco excedentes de produção. Os seringueiros são basicamente extrativistas, atendendo a uma } \\
\text { demanda ativa dos recursos naturais por eles transformados, mas com crescente atividade de } \\
\text { composição de renda, através da agricultura e criação de animais em seu lote. }\end{array}$ \\
\hline Demografia & $\begin{array}{c}\text { Ambos apresentam crescimento demográfico ao longo do tempo. No entanto, no sistema faxinal } \\
\text { tende a existir maiores problemas em função do aumento do número de pessoas e o reduzido } \\
\text { tamanho da área e a baixa disponibilidade de terra para plantar (uma vez que o criadouro não } \\
\text { pode ser desmatado). }\end{array}$ \\
\hline $\begin{array}{c}\text { Características } \\
\text { físicas }\end{array}$ & $\begin{array}{l}\text { O Seringal Porongaba, de acordo com Franco (2006) apresenta clima equatorial quente e úmido } \\
\text { com chuvas bem distribuídas; floresta amazônica (Ombrófila Densa); relevo dissecado com } \\
\text { altimetria baixa (média de } 216 \text { m); solos hidromórficos gleizados eutróficos; rede hidrográfica em } \\
\text { relevo suave, com rios sinuosos em planícies sedimentares. } \\
\text { No Faxinal Sete Saltos, de acordo com Löwen Sahr e legelski (2003); Monteiro e Löwen Sahr } \\
\text { (2005); Moro e Lima (2012) apresenta clima subtropical úmido com chuvas bem distribuída - } \\
\text { pluvial temperado; floresta com araucária (Floresta Ombrófila Mista Montana); relevo ondulado } \\
\text { a fortemente ondulado (média altimétrica de } 975 \text { m); solos não hidromórficos Cambissolos } \\
\text { distróficos e solos hidromórficos gleizados; rede hidrográfica em vales encaixados. }\end{array}$ \\
\hline
\end{tabular}


conclusão

\begin{tabular}{|c|c|}
\hline & Sinergias \\
\hline \multirow[t]{2}{*}{ Ecológicas } & $\begin{array}{l}\text { Relações com meio - Os seringueiros e os faxinalenses notadamente possuem em sua prática os } \\
\text { etnosaberes passados ao longo do tempo de geração a geração, que pode ser traduzida também } \\
\text { como saber tradicional, saber vernacular e práxis vivenciada. Esta característica é, sem dúvidas, } \\
\text { uma das grandes riquezas de povos como aqui estudados, que mostram uma diversidade étnica, } \\
\text { cultural, operacional de grande complexidade. Possuem ainda permeabilidade às condições } \\
\text { exógenas impostas. }\end{array}$ \\
\hline & $\begin{array}{c}\text { Resiliência e adaptabilidade - Aliado à prerrogativa de respeito e interesse por elementos da } \\
\text { natureza, pode-se articular a sinergia em resiliência e adaptabilidade às condições exógenas } \\
\text { impostas. }\end{array}$ \\
\hline \multirow{3}{*}{ Socioculturais } & $\begin{array}{l}\text { Respeito aos recursos naturais - As percepções mais apuradas nas duas representações sociais } \\
\text { estão atreladas ao respeito aos elementos naturais, que são passíveis de transformação em } \\
\text { recursos e ao mesmo tempo são elementos de configuração de importantes vínculos que se } \\
\text { enquadram na paisagem, no lugar e, sobretudo, na constituição da identidade de seringueiros e } \\
\text { faxinalenses. }\end{array}$ \\
\hline & $\begin{array}{l}\text { Conhecimento profundo do território - um aspecto de forte sinergia se dá através do } \\
\text { conhecimento simbólico e concreto do território. Uma vez que suas identidades são definidas } \\
\text { pela paisagem e pelo território, a gestão deste último passa a ser elemento de sobrevivência da } \\
\text { paisagem e da comunidade, em termos organizativos multidimensionais e também em termos de } \\
\text { empoderamento. Claramente em uma situação de conhecer para proteger e se desenvolver. }\end{array}$ \\
\hline & $\begin{array}{l}\text { Resistencia - os povos que habitam estas áreas lutam pela defesa de seus territórios ao longo do } \\
\text { tempo, estabelecendo um estreito elo entre seu modo de vida e a terra que dá sentido às suas } \\
\text { tradições. }\end{array}$ \\
\hline \multirow{3}{*}{ Gestão territorial } & Pressões externas - Ambos enfrentam pressão externa do agronegócio. \\
\hline & $\begin{array}{c}\text { Pressões internas - Presença de ação antrópica em atividades produtivas inseridas ao longo dos } \\
\text { últimos anos. }\end{array}$ \\
\hline & $\begin{array}{c}\text { Áreas protegidas - Tanto os seringueiros do Acre quanto os faxinalenses do Paraná vivem em } \\
\text { unidade de conservação de uso sustentável, RESEX e ARESUR. }\end{array}$ \\
\hline
\end{tabular}

Fonte: os autores

\section{CONSIDERAÇÕES FINAIS}

Constata-se que os grupos analisados possuem uma resiliência notória mensurada pelas formas de uso e ocupação da terra, pela luta de seus direitos e pela potencial adaptação ao meio em que vivem.

As formas de uso e ocupação da terra se materializam na medida em que os grupos entendem o ambiente e dele se utilizam para suas atividades produtivas, culturais, sociais e ecológicas. Os seringueiros da Amazônia e os faxinalenses do Paraná compreendem de forma profunda seu território à medida que suas práxis são desenvolvidas; realizam uma gestão compartilhada de respeito do ambiente e demonstram a adequação e viabilidade de seu modo de vida que interessa pesquisadores, poder público e sociedade. Atravessam igualmente muitas situações de pressões - de várias ordens, desde ambiental até a econômica - contudo as articulações benéficas devem ser evidenciadas de forma a demonstrar considerações factuais de modos de organização e gestão do território em comunidades reconhecidamente tradicionais e articuladas com o ambiente.

Os grupos mencionados reivindicam seus direitos e os buscam coletivamente, sejam em cooperativas, associações ou conselhos. 
Estes indivíduos lutam pela defesa do que restou de seus territórios e resistiram e resistem diante de distintas adversidades ao longo do tempo. Tratam-se de sujeitos históricos que ocupam os espaços que o agronegócio quer "abocanhar", são pessoas que teceram histórias e racionalidades nos ambientes em que vivem, estabelecendo um estreito elo entre seu modo de vida e a terra que dá sentido às suas tradições (LANGARO, 2018, p. 102).

Dialogam com sua cultura e com ambiente que vivem e forma irrestrita. Como produtos de um sistema complexo, são capazes de se autorregular [reorganizar] existindo condições para que isso ocorra como equilíbrio ecológico. Caso contrário, há a entropia, ou desordem dos fatores sistêmicos. Esses grupos, seringueiros e faxinalenses apresentam determinado grau de autopoiese, alicerçados pelos perfis de subsistência e adaptabilidade ao ambiente e aos sistemas sociais, econômicos e culturais. Para a manutenção e recriação dessas comunidades existe a tendência de reprodução de seu sistema tradicional [respeito ao ambiente, ao social e cultural], como também uma tendência modernizadora dentro do tradicionalismo que possibilita ampliar as relações com o mundo externo (LÖWEN SAHR, 2008). Por isso verifica-se um constante potencial de disfuncionamento do sistema tradicional seringal e faxinal.

Assim os elementos mencionados nesse ensaio, que são atributos muito difundidos na biogeografia no ponto de vista físico [organização, reorganização, resistência, resiliência, adaptação, complexidade, entre outros] revestem-se também como atributos fundamentais para uma biogeografia relacionada aos indivíduos humanos.

\section{REFERENCIAS}

ACRE. 2000. Zoneamento ecológico-econômico: recursos naturais e meio ambiente. Governo do Estado do Acre. Programa Estadual de Zoneamento Ecológico-Econômico do Estado do Acre. Rio Branco: SECTMA, 2000.

ALECHANDRE, A. Exploração Florestal e sustentabilidade. Slidshare - Academia amazônica. Tópicos especiais: Teoria e pratica para a construção de uma Amazônia Sustentável. Rio Branco, 2007. Disponível em: <https:/ / pt.slideshare.net/Myris/andrea-alechandre-pfnm-final>. Acesso em: 23 maio 2018.

ALLEGRETTI, M. H. A construção social de políticas públicas. Chico Mendes e o movimento dos seringueiros. Desenvolvimento e Meio Ambiente, n. 18, p. 39-59, jul./dez. 2008.

BRASIL. Instituto Brasileiro de Meio Ambiente e dos Recursos Naturais Renováveis. Plano de Manejo da Reserva Extrativista Chico Mendes - Acre. Brasília 2006. 91 p. Disponível em < http:/ /www.icmbio.gov. br/portal/images/stories/imgs-unidadesoservacao/resex_chico_mendes.pdf>. Acesso em: 23 jan. 2018.

. Decreto 6.040 de 7 de fevereiro de 2007. Institui a Política Nacional de Desenvolvimento Sustentável dos Povos e Comunidades Tradicionais. Disponível em: <http://www.planalto.gov.br/ ccivil_03/_ato2007-2010/2007/ decreto/d6040.htm>. Acesso em: 10 jan. 2018.

CAMARGO, J.C.G.; TROPPMAIR, H. A evolução da Biogeografia no âmbito da ciência geográfica no Brasil. Revista Geografia, Rio Claro, v. 27, n. 3, p. 133-155, jul. 2002.

CAPRA, F. LUISI, P.L. A visão sistêmica da vida. São Paulo: Cultrix, 2014.

CARVALHO, S.M.; FLORIANI, N. (Org.). Faxinal Taquari dos Ribeiros: diálogos interdisciplinares, sustentabilidade e etnoecologia. Ponta Grossa: Ed. UEPG, 2017. 
CHANG, M. Y. Sistema faxinal: uma forma de organização camponesa em desagregação no centro-sul do Paraná. Londrina, IAPAR, 1988. (Informe de Pesquisa, 22).

CHRISTOPHERSON, R. W. Geossistemas: uma introdução à Geografia Física. 7.ed. Porto Alegre: Bookman, 2012.

CNS. Conselho nacional de seringueiros. Relatório sócio econômico e cadastro da Reserva Extrativista Chico Mendes. Rio Branco, Acre 1992. Disponível em: <http:/ / www.chicomendes.org.br/seringueiros13. php>. Acesso em: 30 abr. 2019.

CORREIA, R.L.; GOMES, M.F.V.B. As transformações nos faxinais e suas novas territorialidades: estudo de caso em Pinhão-PR. Revista Pegada, v. 16, p. 102-116, maio 2015.

CRONON, W. Uncommon ground: rethinking the human place in nature. New York: W.W. Norton, 1995.

DIEGUES, A.C. O mito moderno da natureza intocada. São Paulo: HICITEC/ NUPAUB, 1996.

FERREIRA, E.S. A Influência do Sistema Faxinal no Estado Ambiental da Bacia Hidrográfica do Rio Sete Saltos - PR. Ponta Grossa, 2009. Dissertação (Mestrado em Gestão do Território) - Universidade Estadual de Ponta Grossa, UEPG.

FIGUEIRÓ, A. S. Biogeografia: dinâmicas e transformações da natureza. São Paulo, Oficina de textos. 2015.

FLORIANI, N.; CARVALHO, S.M.; FLORIANI, D. et al. Modelos Híbridos de Agricultura em um Faxinal Paranaense: Confluência de Imaginários e de Saberes Agrícolas. In: ENCONTRO NACIONAL DA ANPPAS, 5, 2010, Florianópolis. Anais... p. 1-22.

FRANCO, A. O. Uso do Solo na zona de amortecimento e sua influencia no interior da Reserva Extrativista Chico Mendes - Acre - Brasil. Rio Branco, 2006. Dissertação (Mestrado em Ecologia e Manejo de Recursos Naturais) - Universidade Federal do Acre, UFAC.

; LÖWEN SAHR, C.L. Modo de vida em transformação em áreas de uso sustentável: o caso do Seringal Nova Esperança. Revista NUPEM, v. 11, n. 22, p. 80-91, jan./abr. 2019. Disponível em: <http:// revistanupem.unespar.edu.br/index.php/nupem/article/view/613/358>. Acesso em: 20 maio 2019.

GRZEBIELUKA, D.; LÖWEN SAHR, C. L. Comunidades de faxinal e suas dinâmicas sócio-espaciais: da formação à desagregação de uma tradição no município de Tibagi (PR) - um estudo sobre o faxinal dos empoçados. Revista Geografar, Curitiba, v. 4, n. 1, p. 34-58, jan./jun. 2009.

GOMES, C. V. A. Ciclos econômicos do extrativismo na Amazônia na visão dos viajantes naturalistas. Boletim do Museu Paraense Emilio Goeldi, v. 13, n. 1, jan./abr., 2018.

LANGARO, S. V. Conflitos em comunidades tradicionais: um estudo sobre o Faxinal do Salto - Paraná. Revista Presença Geografia, v. 5, n. 2, p. 96-110, jun./dez, 2018.

LÖWEN SAHR, C.L.; IEGELSKI, F. O Sistema Faxinal no Município de Ponta Grossa: diretrizes para a preservação do ecossistema, do modo de vida, da cultura e das identidades das comunidades e dos espaços faxinalenses. Ponta Grossa: Prefeitura Municipal de Ponta Grossa, 2003. 108 p. (Relatório Técnico).

. Preservação e revitalização do Sistema Faxinal na Região da Mata de Araucária do Paraná: um Projeto Extensionista. Revista Conexão, v. 1, n. 1, p. 42-46, jan./jun. 2005.

Comunidades Tradicionais em racionalidades Duais: reflexões sobre os povos de Faxinais. In: Encontro Nacional da ANPEGE, 6, 2005, Niterói. Anais... Niterói, 2007, p. 1-12.

Os mundos faxinalenses da floresta com araucária do Paraná: racionalidades duais em comunidades. Terr@Plural, v. 2, n. 2, p. 213-226, jul./dez., 2008.

MATURANA, H.; VARELA, F. A árvore do conhecimento: as bases biológicas do entendimento humano. Campinas: Psy II, 1995.

MASCARENHAS, F.S; BROWN, I.F; SILVA, S.S. Desmatamento e incêndios florestais transformando a realidade da Reserva Extrativista Chico Mendes. Desenvolvimento e Meio Ambiente, v. 48, Edição especial: 30 Anos do Legado de Chico Mendes, p. 236-262, nov., 2018. 
MONTEIRO, R.R.; LÖWEN SAHR, C.L. O Sistema Faxinal enquanto forma de organização Cabocla: o caso do Faxinal Sete Saltos de Baixo em Ponta Grossa - PR. In: SIMPÓSIO DE GEOGRAFIA AGRÁRIA, 3, 2005, Presidente Prudente. Anais... p. 1-10.

MORIN, E; MOIGNE, J.L. A inteligência da complexidade. São Paulo: Fundação Peiropolis. 2000.

MORO, R.S.; LIMA, C.N. Vegetação arbórea do Faxinal Sete Saltos de Baixo, Ponta Grossa, PR. Terr@ Plural, Ponta Grossa, v. 6, n. 1, p. 79-90, jan./jun. 2012.

; STANISKI, A.; COMIN, M. et al. La importancia del agrosistema tradicional Faxinal para la conservación de los bosques del sur de Brasil. Ecosistemas, v. 27, n. 3, p. 4-13, 2018. DOI: 10.7818/ECOS.1485

RICKLEFS, R.E. A Economia da Natureza. 5. ed. Rio de Janeiro. Guanabara Koogan. 2009.

PIMENTEL, M.A.S.; RIBEIRO, W.C. Populações tradicionais e conflitos em áreas protegidas. Geousp Espaço e Tempo (Online), v. 20, n. 2, p. 224-237, 2016.

SILVA, S.S. Resistencia Camponesa e desenvolvimento Agrário na Amazônia - Acreana. Presidente Prudente, 2005. Tese (Doutorado em Geografia) - Universidade Estadual de São Paulo, UNESP.

STANISKI, A; FLORIANI, N; STRACHULSKI, J. Estudo etnobotânico de plantas medicinais na comunidade faxinalense Sete Saltos de Baixo, Ponta Grossa - PR. Terr@ Plural, Ponta Grossa, v. 8, n. 2, p. 321-340, jul./ dez. 2014.

SCHÖRNER, A; CAMPIGOTO, J.A. Migrantes no Faxinal e migrações de faxinalenses: Territórios e povos tradicionais. Revista Esboços, Florianópolis, v. 18, n. 25, p. 53-72, ago. 2011.

Data de submissão: 13/jun.//2018

Data de aceite: 27/ jul./ 2019 